\title{
Astronomers fight incursion of phones into radio frequencies
}

[GENEVA] Radioastronomers fighting mobile telephone companies whose transmissions threaten to interfere catastrophically with reception of radio signals at low frequencies are facing a new battle.

The threat comes from several companies that are investigating the use of broadband satellite transmissions at higher frequencies. This would provide higher capacity mobile telephones or Internet services.

The four-week World Radiocommunication Conference-97 (WRC-97), currently taking place in Geneva, seems unlikely to deliver what radioastronomers want guaranteed transmission standards that would assure no harmful overspill emission into parts of the spectrum allocated to another user. Instead, radioastronomers are likely to have to continue negotiating protection of their bandwidths on a case-by-case basis, a procedure in which they have so far mostly been losers.

But the WRC-97 conference, run by the International Telecommunication Union (ITU) - a United Nations body that rules on issues relating to sharing of the spectrum, radio regulations and operational standards - has at least made one decision in radioastronomers' favour. It has agreed to consider at its 1999 meeting the sharing of the spectrum above $70 \mathrm{GHz}$, the highest part of the radio spectrum, which has so far not been targeted commercially because of the expensive technology that would be involved.

Until now radioastronomers have enjoyed free use of this part of the spectrum, which contains a very high density of spectral lines corresponding to important molecules. Several existing facilities are active in this range, as will be the planned next-generation Square Kilometre Telescope.

But radioastronomers have learnt the wisdom of fighting for guaranteed protection before commercial interests appear. The new pressure on the radio spectrum means that companies are gearing up to reserve sections of the millimetre-range spectrum, even though there is as yet no technology to exploit it cost-effectively. This time around, radioastronomers want watertight rules on overspill transmission before companies make specific technical plans.

The radio spectrum was last carved up by the radiocommunication section of the ITU in 1979, and radioastronomy was allocated around two per cent of the whole spectrum. Lack of commercial competition meant that it was allocated 24 per cent of the spectrum above $70 \mathrm{GHz}$.

But commercial interests, particularly

mobile telephone companies, have mushroomed since then. Radioastronomers, accustomed to regular local battles to defend their frequencies against interference from terrestrial broadcasts, found themselves threatened with complete disablement by interference from satellite communications (see below).

The increasing sophistication of mobile phone satellite systems operating at frequencies below $30 \mathrm{GHz}$ threatens to destroy the ability of radiotelescopes to receive important, but weak, radio signals that scientists need to study early events of the Universe.

Such weak signals could be drowned out completely. One standard mobile telephone

\section{Interference threatens Indian radiotelescope}

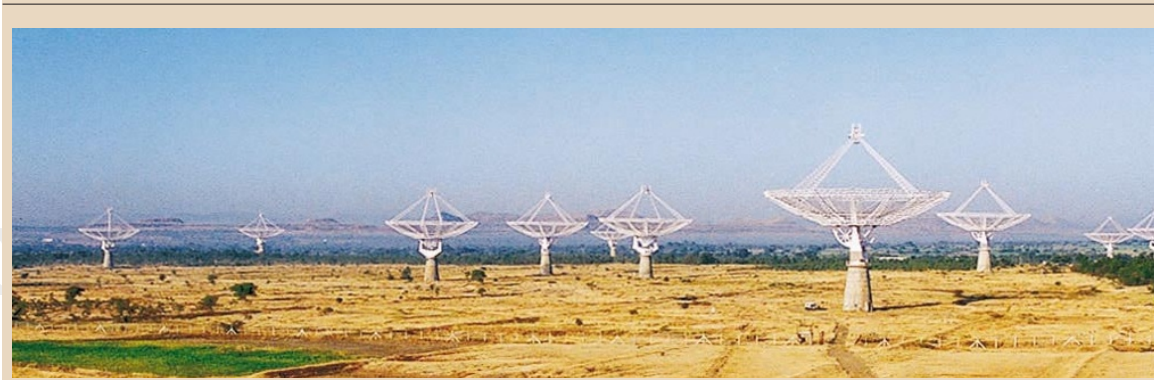

[NEW DELHI] India's radioastronomers are upset about the likely impact of emissions from a new mobile telephone satellite network on the US\$17 million Giant Metre Wave Radio Telescope (GMRT) near Pune (above). The telescope, operated by the Tata Institute of Fundamental Research, is one of the most sensitive in the world.

The astronomers are calling on the government to protect their interests against Iridium, the Motorola subsidiary, which owns the largest share of the global satellite communication system. The company is also building a 'gateway' at a site only $80 \mathrm{~km}$ from GMRT, to service mobile telephone users in most of south Asia.

Astronomers at the Tata Institute's National Centre for Radio Astrophysics in Pune are worried that signals from the satellites to mobile telephones will interfere with observations of the radio emission from hydroxyl $(\mathrm{OH})$ molecules - an important band for exploration of starforming regions in the galaxies. "We cannot allow this to happen," says the centre's director V. K. Kapahi.

The telescope operates in the $38-1,427 \mathrm{MHz}$ frequency range, and there are plans to extend this to $1,670 \mathrm{MHz}$. Once this is done, GMRT will provide a larger collecting area than that of the Parkes Radio Telescope in Australia for survey of the southern sky for $\mathrm{OH}$ emitting clouds, says Govind Swarup, creator of the project. "It would be a pity if we cannot use our best telescope to scan for $\mathrm{OH}$ masers - or look for signals from extraterrestrial intelligence."

The government has taken care not to erect any radio transmitters within 500 $\mathrm{km}$ of the telescope. Several frequency bands of interest to GMRT have also been given protection by the national committee that allocates frequencies for various services. But all this will change when Iridium satellites go commercial next September, says Kapahi.

The satellites will beam signals to phones in the 1,621.35-1,626.5 MHz frequency range which is close to the radioastronomy band of 1,610.6-1,613.8 MHz. The International

Telecommunication Union allows satellite companies to downlink at these frequencies provided no "harmful interference" is caused to radioastronomy, but they still require a licence from the countries served.

Astronomers want the government to put Iridium's licence on hold until they see the full results of tests of the Iridium downlink emissions.

K.S. Jayaraman 
emissions' could be eliminated or masked by technical fixes. But these would be costly.

Radiotelescope operators have refused to accept offers from companies such as the mobile-phone operation Iridium to solve the problem by time-sharing frequencies or by building special transmitting (and therefore potentially interfering) beacons at their sites which could instruct handsets in the vicinity to change frequencies (see Nature 380, 569; 1996).

Companies have rejected suggestions from radioastronomers to change their frequencies, particularly those of downlinks which are the biggest source of potential interference, develop filters for their satellites to block spurious emissions, or cap the number of subscribers making calls at any one time to ensure minimum overspill.

The deadlock continues at the WRC-97 meeting, where radioastronomers' pleas have cut little ice. WRC-97 is finalizing allocations in the 30-60 GHz range for broadband services such as the planned multisatellite system of Telesedic and Alcatel, called Sky
Bridge, as well as Sky station. This is a proposed system of stratospheric balloons which would hang over cities beaming the Internet to their inhabitants, and providing larger capacity mobile telephone links.

Radioastronomers have been using the conference to seek greater protection for their bandwidths at these higher frequencies. "We are worried that these high density bands will be unable to clean up the signals they transmit to avoid radioastronomy frequencies," says Baan.

Radioastronomers are divided about how best to fight the powerful commercial interests against which they are pitted. Some feel that the market atmosphere of the ITU and its World Radiocommunication Conferences is not the right battlefield. Lobbying in this arena is important but has had little effect, says Roy Booth, director of the Swedish Facility for Radioastronomy in Onsala.

In contrast, Booth recently organized a joint declaration from directors of radioastronomy institutes committing them to a global coordinated effort to control the threat from satellite transmissions.

Harvey Butcher, director of the Netherlands Foundation for Research in Astronomy, believes action by governments is the only way to guarantee protection of radioastronomy. "Users with no economic interests are not getting a look-in [at ITU]," he says.

He is taking part in a Megascience Forum on Radioastronomy set up by the Organization for Economic Cooperation and Development last year. He believes that the contacts this brings with government science policy-makers could help to encourage them to provide money for research into technical fixes, such as development of filters, or to establish radio-quiet zones around observatories which satellite companies would be required to observe.

Baan says the ITU relies on financial contributions from industry and has conceded too much to industry in its decision making process. But he says that abandoning the battle within the ITU would be disastrous. "Things for radioastronomers will get worse before they get better."

Alison Abbott

\section{Congress moves swiftly to protect academy's independence}

[WASHINGTON] The US Congress was poised at the beginning of this week to exempt the National Academy of Sciences (NAS) from the Federal Advisory Committee Act (FACA), ending a year of uncertainty about how the academy prepares scientific and technical advice for the US government.

In the early hours of Monday, the House of Representatives passed a bill allowing the exemption, while requiring the academy to take several steps to open up its processes to the public. The Senate was expected quickly to pass a similar bill, which President Bill Clinton is ready to sign into law.

Congress has responded with unusual haste after a Supreme Court decision last week left the academy complex facing restrictions which Bruce Alberts, the president of the academy, said would prevent it from functioning independently of the government.

Committees organized by the academy would be more open to public scrutiny under the planned legislation. But the National Research Council (NRC), the executive arm of the academy, would still appoint and manage its own study committees, which academy officials have always said is their top priority.

As expected, the Supreme Court had refused to consider an appeal by the NAS against the decision of a lower court forcing NRC committees to operate under the rules of FACA (see Nature 386, 309; 1997). Those rules include allowing public attendance at most meetings, and giving federal agency employees responsibility for the setting up and management of advisory committees.

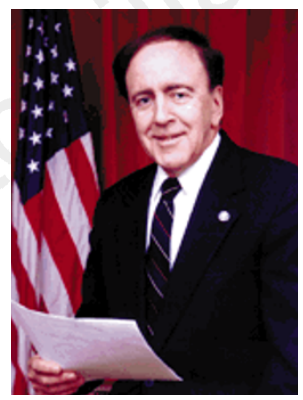

Horn: 'broad agreement' on need for exemption.
Academy officials argued that placing NRC committees under the direct control of federal officials whose programmes are under scrutiny would compromise their independence.

Having lost in the courts, the academy has taken its case to Congress. Stephen Horn (Republican, California), who chairs a House of Representatives subcommittee in charge of government management issues, was largely responsible for drafting legislation exempting the NAS from the act.

At a hearing last week, Horn said there was "broad agreement" in both houses of Congress and in the Clinton administration to grant such an exemption.

But the academy has promised to take some steps to open its operations to the public. The names, biographies and brief conflict-of-interest disclosure statements of each member of an academy study panel would be posted on the Internet.

The public would then have a period, perhaps 20 days, in which to comment. It would be "totally up to the academy's discretion" what to do with those comments, says William Colglazier, the NRC's executive director.

The names and biographies of external reviewers who evaluate completed NRC reports before they are released would also be posted. At present, the reviewers are anonymous, and Colglazier admits that releasing their names might make it more difficult to recruit volunteer reviewers. The academy would encourage public attendance at committee fact-finding meetings (which are already open) by posting notices on the Internet. Meetings involving internal deliberations of a committee or report writing would remain closed.

Alberts said at last week's hearing that these measures would "let as much sunshine in as possible without changing the independent nature of the advice that we give”.

Christopher Paine of the Natural Resources Defense Council (NRDC) calls the academy's concessions to openness "a step in the right direction". The NRDC successfully sued to prevent the Department of Energy from using an academy study on its planned National Ignition Facility earlier this year on the grounds that it had not operated under the act's rules (see Nature 385,$755 ; 1997)$.

But Paine would like to see all NRC meetings open to outside observers and to have greater public accountability in the composition of the council's committees.

Paine's group will release a report this week detailing what he calls an "egregious failure" in the academy's system of internal controls in connection with the report on the ignition facility.

According to the NRDC, the energy department disbanded its own advisory panel and solicited the academy report instead because it thought it might be more favourable to the facility. 